\title{
Psicólogos em secretarias de educação paulistas: concepções e práticas
}

\author{
Marilene Proença Rebello de Souza \\ Universidade de São Paulo - São Paulo - SP - Brasil \\ Aline Morais Mizutani Gomes \\ Universidade de São Paulo - São Paulo - SP - Brasil \\ Ana Karina Amorim Checchia \\ Universidade de São Paulo - São Paulo - SP - Brasil \\ Juliana Sano de Almeida Lara \\ Universidade de São Paulo - São Paulo - SP - Brasil \\ Marcelo Domingues Roman \\ Universidade Federal de São Paulo - Santos - SP - Brasil
}

\begin{abstract}
Resumo
Este artigo tem como objetivo apresentar e analisar concepções e práticas de psicólogos que atuam em políticas públicas de Educação Básica no estado de São Paulo. Foram entrevistados psicólogos de nove municípios paulistas cujas práticas encontram-se alinhadas com as principais discussões na área de Psicologia Escolar e Educacional referentes a uma atuação institucional e alicerçada na realidade social e cultural da escola. A atuação dos profissionais é analisada sob três eixos: a) história de constituição da modalidade de atendimento; b) práticas desenvolvidas e c) concepções que embasam esta atuação. De modo geral, constatam-se: a) grande diversidade de formas de contratação de psicólogos, demonstrando a necessidade de uma política nacional de inserção de psicólogos na rede pública de educação, b) concepções e práticas centradas em intervenções no processo de escolarização, na formação de professores e em críticas à medicalização da Educação.
\end{abstract}

Palavras-chave: Atuação do psicólogo; pesquisa qualitativa; Educação Básica.

\section{Psychologists in São Paulo Education Department: conceptions and practices}

\begin{abstract}
This article aims to present and analyze the conceptions and practices of psychologists who work in public policies of Basic Education in the state of São Paulo. Psychologists were interviewed from nine cities, whose practices are in line with the main discussions in the area of School and Educational Psychology related to an institutional action and based on the social and cultural reality of the school. The work of the professionals is analyzed under three axes: a) history of constitution of the service modality; b) practices developed and c) conceptions that support this action. In general, there are: a) great diversity of ways of hiring psychologists, demonstrating the need for a national policy for the insertion of psychologists in the public education system, b) conceptions and practices focused on interventions in the schooling process, Teacher training and criticism of the medicalization of Education.
\end{abstract}

Keywords: Psychologist performance; qualitative research; Basic education.

\section{Psicólogos en secretarias de educación paulistas: concepciones y prácticas}

\section{Resumen}

Este artículo tiene como objetivo presentar y analizar concepciones y prácticas de psicólogos que actúan en políticas públicas de Educación Básica en el estado de São Paulo. Se entrevistaron psicólogos de nueve municipios paulistas cuyas prácticas se encuentran de acuerdo con principales discusiones en el área de Psicología Escolar y Educacional referentes a una actuación institucional y basada en la realidad social y cultural de la escuela. La actuación de los profesionales es analizada bajo tres ejes: a) historia de constitución de la modalidad de atención; b) prácticas desarrolladas y c) concepciones que fundamentan esta actuación. De modo general, se constatan: a) gran diversidad de formas de contratación de psicólogos, demostrando la necesidad de una política nacional de inserción de psicólogos en la red pública de educación, b) concepciones y prácticas centradas en intervenciones en el proceso de escolarización, en la formación de profesores y en críticas a la medicalización de la Educación.

Palabras clave: Actuación del psicólogo; investigación cualitativa; Educación Básica. 


\section{Introdução}

A Psicologia Escolar e Educacional tem desenvolvido nos últimos trinta anos, importante discussão em relação à formação/atuação do psicólogo no campo educacional em busca de perspectivas críticas que concebam o fenômeno educacional nas dimensões pedagógica, institucional, relacional, social e política, visando superar modelos tradicionais de atuação na área, marcadamente calcados na avaliação psicodiagnóstica e no atendimento clínico individualizante (Souza, 2010).

As críticas a este perfil profissional do psicólogo e às concepções adaptacionistas da Psicologia começaram a ter destaque no Brasil na década de 1980. Desde então, compreender a atuação psicológica no campo educacional em uma perspectiva crítica passou a ser objeto de estudo de vários pesquisadores brasileiros. Trabalhos de pesquisa e análise da produção científica no Estado de São Paulo realizados por Tanamachi $(1992,1997,2002)$ revelam que parte significativa desta produção de 1984 a 2001 está centrada nesta perspectiva ${ }^{1}$.

Com base nesse enfoque, afirma-se a necessidade de conhecer a realidade escolar, explicitando os processos que acontecem intramuros, no dia a dia do fazer docente, visando estudar a escola concreta, a escola construída no interior das práticas educacionais (Ezpeleta \& Rockwell, 1986; Rockwell, 2009). Assim sendo, a atuação do psicólogo escolar passa a ter um novo sentido no contexto educacional, centrando-se no processo de produção das práticas de escolarização. A compreensão do fenômeno da escolarização na sua complexa constituição possibilitou, nessa perspectiva teórica, considerar que os encaminhamentos feitos pela escola aos psicólogos são expressões das formas como se configuram o cotidiano escolar e as práticas educativas. Denominam-se esses encaminhamentos de "queixa escolar" (Souza, 1996).

Publicações nesta área - tais como as de Patto (2000, 2005); Tanamachi, Rocha e Proença (2000); Freller (2001); Meira e Antunes (2003a, 2003b); Machado e Proença (2004); Viégas e Angelucci (orgs.) (2006); Souza (2010); CRP e GIQE (2010); e Leal, Facci e M. Souza (2014) - oferecem importantes subsídios, tanto para desvelar os determinantes sociais e históricos que conformam as relações entre a Psicologia e a Educação, quanto para reafirmar a possibilidade da construção desta perspectiva crítica no campo da pesquisa e da atuação profissional.

Dessa forma, torna-se necessário investigar como esta discussão acadêmica tem influenciado a prática profissional e, sobretudo, compreender como psicólogos que atuam na área da Educação têm se apropriado de tais contribuições teóricas. Além disso, é relevante analisar limites e possibilidades identificados por psicólogos em suas propos-

1 Tanamachi publicou resumo deste levantamento no capítulo intitulado "Mediações Teórico-Práticas de uma visão crítica em Psicologia Escolar" do livro organizado por Tanamachi, E. R., Rocha, M., \& Proença, M. (2000). Psicologia e Educação: desafios teórico-práticos (2a. ed.). São Paulo: Casa do Psicólogo. tas de intervenção, explicitando desafios que a Psicologia, enquanto ciência e profissão, precisa ainda enfrentar a fim de contribuir para a construção de uma escola que cumpra com suas finalidades sociais.

Com base nessas reflexões, o presente trabalho destaca as principais questões apontadas por psicólogos da rede de Educação Básica, que realizam práticas que coadunam com uma perspectiva crítica em Psicologia Escolar e Educacional. Ou seja, o recorte deste artigo centra-se no discurso desses profissionais, buscando identificar em que contexto suas práticas se constituíram, que concepções teóricas fundamentam sua atuação e como realizam um trabalho de Psicologia, com ênfase em seus alcances e limites.

\section{Método}

As discussões que ora apresentamos são oriundas de uma pesquisa realizada no período de 2006 a 2010, que contou com a participação de pesquisadores dos estados de São Paulo, Rondônia, Acre, Minas Gerais, Bahia, Santa Catarina e Paraná, e que foi recentemente publicada no livro intitulado Atuação do psicólogo na Educação Básica: concepções, práticas e desafios (Souza, Silva, \& Yamamoto, 2014).

No estado de São Paulo, dos 645 municípios existentes, foram contatados 133, sendo que em 61 deles atuavam psicólogos nas Secretarias de Educação. Participaram efetivamente da pesquisa, 109 psicólogos de municípios paulistas. Para conhecer mais amplamente o trabalho desenvolvido nos serviços de Psicologia desses municípios, realizamos os seguintes procedimentos investigativos: 1) análise documental da produção bibliográfica sobre a atuação do psicólogo na Educação; 2) aplicação de questionários, com questões referentes a: formação acadêmica, cargo e função na Secretaria de Educação, público-alvo, nível de ensino, modalidades de atuação, projetos profissionais e autores de referência; 3) realização de entrevistas.

Tendo em vista os objetivos de pesquisa, optou-se por entrevistar somente profissionais cujas respostas ao questionário expressavam elementos do que se denomina na literatura da área uma atuação na perspectiva crítica em Psicologia. Para tanto, utilizaram-se os seguintes critérios de criticidade propostos por Tanamachi (1997) e Prilleltensky \& Fox (1997), com base em princípios do pensamento marxista: consideração das múltiplas determinações sociais, econômicas, políticas, históricas dos fenômenos humanos; articulação entre concepções teóricas e a prática profissional considerando as contradições da realidade social; referência a autores do pensamento crítico e o modo como são apropriados; explicitação de um compromisso ético-político com a transformação da Psicologia, da Educação e da Sociedade.

Assim, do conjunto de questionários aplicados, foram selecionados profissionais de Secretarias de Educação de nove municípios paulistas nos quais mais identificamos esses elementos de criticidade. Vale ressaltar que consideramos não existir uma atuação puramente crítica, pois 
entendemos que as práticas são compostas tanto por elementos que consideram os determinantes sociais, históricos e políticos imbricados no fenômeno educacional, quanto por elementos centrados em explicações individualizantes e naturalizantes para os problemas de escolarização.

Durante visita dos pesquisadores a cada um dos serviços de Psicologia, foram realizadas entrevistas com os psicólogos, tanto individualmente como em grupo, mediante a utilização de um roteiro semiestruturado, e gravadas em áudio (Bogdan \& Biklen, 1994). A entrevista tem sido um dos principais procedimentos de pesquisa em Psicologia Escolar e Educacional, por possibilitar maior proximidade com o participante da pesquisa e gerar aprofundamento das questões a serem investigadas (Lüdke \& André, 1986).

As questões propostas para os entrevistados basearam-se em três grandes eixos: a) motivos e interesses que constituíram no município a montagem de um serviço de Psicologia, bem como a trajetória dos profissionais e equipes nele existentes; b) concepções teóricas que norteiam ações dos psicólogos; c) modalidades de atuação profissional dos psicólogos, bem como dificuldades e impasses presentes nessa prática e alternativas de superação.

A seguir, apresentaremos alguns dos principais aspectos referentes à atuação desses profissionais na rede básica de Educação.

\section{Resultados e Discussão}

Optamos por iniciar pela apresentação do histórico dos serviços de Psicologia nas secretarias municipais de Educação por considerarmos que reconstituir o caminho percorrido pelos profissionais é fundamental para compreender como as práticas atuais puderam ser construídas. Da mesma forma, conhecer as condições de trabalho dos psicólogos permite entender entraves institucionais e potencialidades nas quais os psicólogos se apoiam para construir alternativas de trabalho face às problemáticas existentes. Em seguida, exporemos as concepções teóricas que embasam as práticas dos psicólogos, visto que as atividades profissionais expressam posições teórico-metodológicas, vinculadas a determinadas visões de homem e de mundo, que são veiculadas nas opções de práticas que o profissional decide empregar. Por fim, passaremos às práticas propriamente ditas, explicitando as demandas que chegam aos psicólogos e as modalidades de atuação que são desenvolvidas para atendê-las.

\section{Constituição dos serviços de psicologia nas secretarias municipais de Educação}

A maioria dos serviços em que os psicólogos estão inseridos surgiu a partir de 2000. Chamou atenção o fato dos serviços terem sido criados e se estruturarem de forma tão diversa: a) por iniciativa de um grupo de profissionais (psicólogos e/ou pedagogos) que estava inserido na rede; b) por iniciativa do secretário de Educação; c) pela necessidade de se adaptar à política de educação inclusiva; d) pela pressão dos pais de crianças com deficiências físicas; e) por iniciativa de uma psicóloga, que observava a grande demanda vinda da Educação para a Saúde.

Assim, observaram-se tanto movimentos individualizados ou coletivos que partiram da reflexão e envolvimento direto dos profissionais ou da comunidade, quanto o desdobramento de ações oriundas de nível macro-político. Além disso, enquanto alguns serviços se constituíram em núcleos com departamentos específicos para cada nível de ensino e com equipes multidisciplinares, outros concentraram o trabalho em torno de um único profissional.

Em relação à forma de contratação do psicólogo, todos disseram ter ingressado por meio de concurso público, entretanto, nem todos foram contratados pela Secretaria de Educação. Alguns o foram pela Secretaria de Saúde e outros, ainda, fazem parte do quadro da Prefeitura e naquele momento estavam lotados na Educação. Embora todos atuem como psicólogos, a denominação do cargo variou: psicólogo, psicólogo escolar, professor e supervisor de ensino. Assim, nem sempre a via de acesso à Secretaria de Educação era direta.

Essa diversidade na criação dos serviços e nas formas de contratação dos profissionais demonstra que o espaço da Psicologia na Educação ainda é bastante instável, o que se relaciona com a ausência de uma política nacional que insira o psicólogo na rede pública de Educação² (Souza \& Rocha, 2011). Tal ausência está ligada a reminiscências das críticas a sua atuação tradicional neste campo, principalmente a partir das décadas de 1970 e 1980, pois essas críticas contribuíram, em um primeiro momento, para um recuo da atuação de psicólogos junto às escolas e um fortalecimento da identidade desses profissionais como pertencentes à área da saúde, o que culminou com o seu não reconhecimento como profissionais da Educação pela Lei de Diretrizes e Bases da Educação Nacional de 1996 (Souza, 2011).

Mesmo diante de um quadro geral de ausência de políticas públicas para a inserção de psicólogos na Educação, em um dos municípios pesquisados existe plano de carreira para o psicólogo, que foi incluído no Plano de Carreira do Magistério após muita reivindicação, como nos relata um dos entrevistados:

\footnotetext{
Por ideologia e para manter as conquistas, muitas pessoas lutaram para ficar aqui. Então, o que fizemos foi buscar nossos direitos nesse sentido, e ganhamos essa batalha. Ganhamos uma batalha de poder estar na Educação; e a nossa nomenclatura, mudou de "Psicólogos III" para "Psicólogo Escolar". A maior conquista: firmar que uma equipe de psicólogos do município foi capaz de ser incluída num Plano de Carreira do Magistério (Psicólogo 01).
}

2 Neste momento, encontra-se em tramitação projeto de lei que dispõe sobre a atuação de psicólogos e assistentes sociais na rede básica de Educação (PL 3688/2000) visando estabelecer parâmetros nacionais para a inserção desses profissionais. 
Em todos os outros serviços não há qualquer tipo de perspectiva de progressão na carreira previamente estabelecida. Os critérios e prazos para aumento de salário são bem variáveis: alguns consideram o bom desempenho, outros a obtenção de títulos e realização de cursos ou o tempo de serviço. Há tanto regime estatutário como celetista. Foram frequentes as queixas sobre baixa remuneração e precárias condições de trabalho.

Na maioria dos municípios observou-se que os psicólogos trabalham em conjunto com outros profissionais, entre eles: fonoaudiólogos, fisioterapeutas, assistentes sociais, terapeutas ocupacionais e principalmente pedagogos, formando equipes multidisciplinares dentro das Secretarias de Educação ou ao menos parcerias. Em ambos os casos, nota-se uma preocupação em desenvolver um trabalho mais ampliado, articulando toda a rede envolvida com o contexto educacional.

Os dados revelam que existem municípios pequenos com grandes equipes de psicólogos e municípios grandes com apenas um psicólogo atendendo à demanda de todas as escolas. Assim, observa-se que o número de psicólogos contratados não está necessariamente relacionado ao tamanho da demanda municipal.

A maioria dos serviços está sujeita a mudanças de gestão municipal. No discurso dos psicólogos foi possível notar uma insegurança quanto ao futuro do trabalho que é desenvolvido e a necessidade de reafirmar frequentemente a sua relevância. Como os serviços não costumam fazer parte do organograma da Secretaria, as mudanças de dirigentes provocam alterações freqüentes no quadro de profissionais que integram a equipe, o que dificulta a continuidade e a consolidação dos trabalhos, como ilustra a fala abaixo: "Isso que é um problema sério. A gente fica preocupado... Agora tem um grande trabalho que a gente está montando, depois, de repente, muda a prefeitura e diz: 'Não me interessa esse trabalho de inclusão'. Pode acontecer...” (Psicólogo 02).

Tanto a falta de critérios para estabelecer uma relação proporcional entre o número de profissionais e o tamanho da demanda municipal quanto a instabilidade do trabalho frente a mudanças de gestão relacionam-se com a ausência da regulamentação estatal para a atuação do psicólogo na Educação Básica, como mencionado anteriormente.

\section{Concepção teórica dos psicólogos}

Ao longo das entrevistas, os psicólogos citaram os seguintes autores, cujas obras norteiam seu trabalho: Foucault, Vigotski, Paulo Freire, Marx, Maria Teresa Eglér Mantoan e autores da Psicologia Escolar como Maria Helena Patto, Marilene Proença, Marisa Meira, Marilda Facci, Adriana Marcondes Machado e Yara Sayão. Além disso, houve referências a conhecimentos de Desenvolvimento Infantil, Teorias Psicodinâmicas, Psicanálise, Teoria Sistêmica, Psicologia Social, Filosofia e Educação. Nota-se, assim, uma grande diversidade de linhas teóricas que embasa a atuação desses profissionais.
De modo geral, os entrevistados revelaram elementos que configuram uma concepção crítica de Psicologia e Psicologia Educacional ao afirmarem que o psicólogo escolar deve apresentar um olhar crítico em sua atuação, que não deve se pautar em um atendimento clínico tradicional ou no encaminhamento de alunos para a área da Saúde e, sim, no enfrentamento das questões no próprio âmbito escolar: "Nesse tipo de trabalho institucional, a visão é educacional. Não é a psicóloga clínica, que vai lá pra avaliar". (Psicólogo 07). Ou seja, fizeram referência a uma atuação voltada para o processo de escolarização, no qual o posicionamento do psicólogo escolar está pautado em assessorar a escola a cumprir seus objetivos educacionais, em vez de oferecer tratamento e cura dos problemas individuais de cada aluno:

\begin{abstract}
...E a partir daí, nós tivemos que desconstruir tanto essa visão de que a Psicologia vem curar, tratar as crianças, bem como construir e conquistar um fazer na área educacional. E havia algumas dúvidas de que o psicólogo pudesse discutir questões da escola, pois não tínhamos a prática pedagógica, mas o que discutíamos era o processo de ensino-aprendizagem (Psicólogo 08).
\end{abstract}

Assim, se, por um lado, o psicólogo escolar se depara com dúvidas quanto às suas possibilidades de atuação frente às demandas escolares por não ter, na maioria das vezes, a experiência da prática docente em sala de aula, por outro lado, percebe que é possível realizar um trabalho na escola dentro da especificidade do conhecimento psicológico, ao enfocar as relações institucionais e práticas pedagógicas que compõem o contexto escolar e influenciam o processo ensino-aprendizagem.

A relevância de se trabalhar com a formação de professores de forma reflexiva foi apontada pelos entrevistados ao afirmarem que a atuação do psicólogo escolar consiste em trabalhar com os professores sobre as relações que configuram o contexto escolar, com o objetivo de contribuir para o fortalecimento do papel dos educadores na escola e apropriação de seu trabalho, bem como para a transformação de seu olhar em relação aos alunos, atentando para os recursos e potenciais destes. Dessa forma, a fala dos psicólogos se aproxima de referências da área de Psicologia Escolar a respeito do trabalho com professores, que visam, por meio da reflexão teórica, auxiliar na produção de novos sentidos para a ação docente, de forma a potencializá-la (Aguiar, 2002; Galdini \& Aguiar, 2003).

O trabalho do psicólogo como mediador entre os participantes do contexto escolar foi enfatizado pelos entrevistados, que destacaram a importância de se considerar todos os participantes envolvidos no contexto educacional. Também atribuíram ao psicólogo escolar contribuições relacionadas à reflexão, sistematização, desconstrução e reconstrução das práticas escolares. Essas concepções dialogam com proposições desenvolvidas na Psicologia Escolar que enfatizam o caráter institucional da intervenção do psicólogo na escola, em sua participação como ouvinte dos discursos institucionais e em sua contribuição como auxiliar 
na emergência de transformações (Kupfer, 2010; Sayão \& Guarido, 2010).

Deve-se ressaltar que foi possível identificar no discurso de alguns psicólogos uma concepção ancorada na constituição histórico-cultural dos fenômenos humanos, nos momentos em que criticaram a abordagem do psicólogo voltada apenas para questões individuais ou biológicas, além de se destacar a necessidade de buscar aportes em outras áreas do conhecimento, como a Sociologia e a Filosofia da Educação, para poder articular os aspectos sociais e históricos à reflexão sobre os processos educativos:

\begin{abstract}
Mas, sem a Filosofia, para estar ajudando, a Filosofia da Educação, para gente conseguir pensar por que as coisas acontecem, a Psicologia sozinha seria sim esse formato biologizante, essa coisa clínica. Então a Filosofia ajuda muito com essa questão social, a Sociologia. Então muitas vezes eu falo para os professores: "Como a gente pode pensar em tudo que está acontecendo agora, se a gente não pensar em Marx?" A questão das influências do capitalismo nisso tudo, nas atitudes que a gente tem. Então, como a Filosofia não pode ajudar? (Psicólogo 09)
\end{abstract}

Conforme apontaram alguns entrevistados, um dos temas que compõem o questionamento e a reflexão propiciados pelo psicólogo consiste na crítica à medicalização na Educação e à patologização no contexto escolar. Um psicólogo questiona o fato de inúmeras crianças saudáveis serem medicadas em função de queixas escolares, muitas vezes como um meio de controle do comportamento. Diante disso, destacou a necessidade de se discutir, informar e refletir com os profissionais da escola sobre o processo de medicalização, denunciando, inclusive, a influência da indústria farmacêutica nesse processo. Foi evidenciada a necessidade premente de crítica, por parte do psicólogo, à redução de questões educacionais a fatores orgânicos:

Eu questiono muito a questão da medicação que é feita até dentro da escola. A escola se tornou um pequeno manicômio... Antes era uma caixinha com duas Ritalinas, agora já é uma caixa de sapatos; vai ter que arrumar uma caixa de televisão para trazer aqui para a escola. As crianças estão tomando Ritalina na escola... Crianças estão tomando medicamentos, crianças saudáveis... para controle de comportamento. E o pessoal embarca, porque é barata a Ritalina, o que é caro é o "Concerta"... O que eu não concordo é com essa patologização excessiva; tudo é doente! Tudo é dislexia, discalculia, disgrafia, disortorgrafia, tudo é "Dis"! Ninguém teve a letra feia na infância entre os professores? Ninguém comia uma letrinha ou tinha problema de fala? (Psicólogo 09).

A relevância de se romper com rótulos pré-estabelecidos e diagnósticos atribuídos aos alunos, bem como de problematizá-los com os professores, também foi apontada. No discurso dos psicólogos, comparece tanto a referência específica à necessidade de "desconstrução" de certos diag- nósticos - como a dislexia e o TDAH -, quanto a crítica à realização tradicional da avaliação psicológica, de um modo geral.

Dessa maneira, os entrevistados demonstram acompanhar as discussões presentes na Psicologia Escolar a respeito da crítica à medicalização da Educação (Conselho Regional de Psicologia de São Paulo \& Grupo Interinstitucional Queixa Escolar, 2010), e mostram que têm buscado formas de atuação coerentes com essas concepções, conforme veremos a seguir.

\section{Modalidades de atuação dos psicólogos}

Neste tópico analisaremos as modalidades de atuação dos psicólogos a partir de três questões norteadoras: a) quem demanda o trabalho do psicólogo; b) qual o tipo de demanda que se apresenta; c) que estratégias tais profissionais desenvolvem frente às demandas.

De modo geral, o trabalho de psicólogos é demandado, prioritariamente, pelas escolas da respectiva rede municipal de ensino. Porém, também pode ser solicitado por outros agentes, como o Conselho Tutelar ou órgãos da Secretaria de Saúde.

As demandas oriundas das escolas são geralmente formuladas por professores, mas também pela equipe gestora, como direção, orientadores educacionais e coordenadores pedagógicos. Grande parte delas centra-se em casos individuais de alunos. São principalmente pedidos de avaliação psicológica para verificação da existência de transtornos ou deficiências mentais que possam atrapalhar a aprendizagem e para ajuste de comportamentos indesejáveis, como indisciplina e agressividade. Essas solicitações fazem parte do fluxo de encaminhamento de alunos para salas de recuperação de ciclo, bem como para atendimento educacional especializado e salas de recursos, previstos na Política Nacional de Educação Inclusiva (Ministério da Educação, 2001, 2008).

Sabemos que Psicologia e Educação historicamente foram cúmplices na culpabilização exclusiva do aluno e de sua família pelo fracasso escolar e, assim, se auxiliaram mutuamente em ocultar os aspectos históricos, sociais e políticos do processo educacional (Bock, 2003). Dessa forma, a demanda dos educadores aos psicólogos em grande parte representa essa cumplicidade ideológica, ainda fortemente presente no campo educacional. A Psicologia Escolar em uma perspectiva crítica aponta para a necessidade de romper com as explicações pseudocientíficas, que buscam situar a origem dos problemas educacionais no aluno e em sua família, pela via de uma reflexão crítica sobre as práticas sociais e escolares que os produzem (Meira, 2002).

Em concordância com essa perspectiva, há um esforço de vários psicólogos em tentar mudar o entendimento do professor sobre o papel da Psicologia no contexto educativo. Assim, embora eles relatem que ainda recebem muitos pedidos da escola para que sejam realizadas avaliações e encaminhamento para atendimento clínico de crianças "com 
problemas", há um forte movimento na direção da reflexão conjunta com os professores sobre a produção da queixa escolar:

[...] no início tinha-se ainda, pela escola, um desejo de que a Psicologia iria curar toda essa defasagem. Então nós fomos desconstruindo um pouco isso. Discutindo com a equipe escolar o ser criança, suas necessidades, seu desenvolvimento e, somente nos casos com real necessidade, encaminhávamos para atendimento psicoterápico... A intenção era olhar essa escola primeiro, olhar essa criança, e não somente ela enquanto aluno; discutir e refletir com a equipe escolar os motivos da menção de que ela (criança-aluno) era um ser não aprendente e, por conta disso, o responsável por esta não aprendizagem, tendo então de ser encaminhado para tratamento. (Psicólogo 03).

Além dessas, há demandas de cunho coletivo ou institucional, como o trabalho com uma turma em sala de aula, a discussão de temas concernentes à Psicologia, como aqueles relativos à sexualidade, preparação para ingresso no mundo do trabalho, questões de aprendizagem, desenvolvimento e deficiência, com alunos, pais e/ou educadores e formação de professores e gestores. Os psicólogos também indicaram que as discussões e formações oferecidas podem se constituir em espaço para os educadores pensarem e questionarem suas práticas e concepções.

Parte significativa dos psicólogos declarou trabalhar especificamente com Educação Especial ou inclusão escolar, apontando outras demandas além das discriminadas acima, tais como: inserção e acompanhamento escolar de crianças e adolescentes com necessidades educacionais especiais - demanda geralmente encaminhada pelo Conselho Tutelar -, formação de classes especiais e seleção de professores especializados.

Entre os pedidos encaminhados pelo Conselho Tutelar e órgãos da Secretaria da Saúde estão, além da inclusão escolar, a avaliação e o acompanhamento de vítimas de violência, de crianças expostas a condições de extrema vulnerabilidade social e de alunos medicados com psicotrópicos. Também foram relatadas solicitações de atuação em questões que se relacionam com a participação da comunidade nos órgãos de controle social, como os conselhos de Educação, de defesa da mulher e de orçamento participativo.

A maior parte dos trabalhos é realizada no interior das escolas. Alguns psicólogos mencionaram desenvolver projetos que seguem um planejamento específico e que têm objetivos determinados de acordo com as demandas identificadas. Nestes casos, os psicólogos permanecem durante certo tempo na escola para conhecer sua realidade, conversar com a equipe e, assim, levantar as necessidades da instituição.

De maneira geral, o foco da atuação do psicólogo se dá no âmbito institucional, no processo de escolarização, assim nomeado pelos entrevistados. Essa perspectiva não exclui ações mais individualizadas junto à criança encaminhada e às famílias, mas expande seu raio de ação ao professor e outros profissionais da escola e fora dela. Vários psicólogos mencionaram que procuram em seu trabalho potencializar as ações dos diversos atores envolvidos no processo educacional, tendo como objetivo tirar o foco dos alunos e centrando-se na mediação das situações e na participação de sujeitos que podem, de alguma forma, ajudar a atender a demanda. Por isto, as conversas e a participação nas reuniões têm como objetivo responsabilizar os vários sujeitos. Neste contexto, as famílias são frequentemente chamadas, e nestes encontros busca-se trazê-las como aliadas do processo de escolarização.

Há projetos em que o foco de trabalho é o professor, principalmente por meio de atividades de formação, cujos temas são escolhidos a partir do pedido das escolas ou por sugestões da equipe. Essa formação se dá nas reuniões pedagógicas regulares ou em horários fora da jornada de trabalho - à noite ou aos sábados -, geralmente sob a forma de cursos específicos, como Braile e LIBRAS, contando com a participação de formadores externos.

Para alguns psicólogos, o centro do trabalho deve ser o diretor da escola, ou seja, o foco de sua intervenção está na orientação pedagógica e administrativa ao diretor, além de supervisionar e mediar relações entre o diretor e os professores, ou de forma mais ampla, entre diretor e a comunidade escolar. O trabalho envolve a orientação para elaboração do projeto pedagógico, incluindo a discussão sobre o embasamento teórico utilizado.

Vários psicólogos informaram que realizam atendimento individual ou em grupo com as crianças encaminhadas, participam de atividades em que se discutem temas como drogas e sexualidade ou realizam ações específicas voltadas para o combate à evasão escolar. A forma como cada profissional vai realizar estes grupos pode variar: encontros quinzenais ou semanais; podem ser na sala de aula, na biblioteca ou em outro espaço. O material utilizado também varia: vídeo, gráfico e/ou dinâmicas de grupo. Ao final do ano, geralmente é feita uma avaliação do projeto desenvolvido a partir da qual são apontadas as falhas e reconhecidos os objetivos atingidos.

Em alguns municípios foram criados centros de atendimento utilizados, sobretudo, como apoio à inclusão escolar. Nesses centros, os alunos apontados pela escola são avaliados e encaminhados para os serviços educacionais ou de saúde mais apropriados às necessidades de cada caso. Os psicólogos evidenciaram uma preocupação com o rigor com que os alunos devem ser encaminhados para atendimento educacional especializado, bem como para médicos, que freqüentemente lançam mão de psicotrópicos para controle do comportamento, humor ou estado de atenção. Há, enfim, um explícito esforço para reverter o grande número de encaminhamentos para esses serviços ou atendimentos.

Os psicólogos explicitaram, ainda, críticas à homogeneização e padronização presentes no contexto escolar. Esse aspecto se tornou mais presente nos discursos sobre Educação Inclusiva, em que psicólogos afirmaram que na escola não se sabe lidar com as diferenças e questionaram práticas pedagógicas que contemplam apenas os alunos 
considerados "normais". A dimensão segregadora da escola também foi apontada ao se mencionar que o aluno é considerado "problemático" caso não se enquadre nos padrões determinados. Diante disso, um psicólogo destacou a importância de se atentar para os recursos e potencial dos alunos, em oposição à ênfase atribuída às faltas ou limitações: "Eu quero que as pessoas enxerguem com outros olhos, vejam o que ele consegue fazer, não só o que ele não consegue" (Psicólogo 04).

As equipes que atuam junto à Educação Inclusiva podem ser classificadas em três grupos: 1) aquelas mais vinculadas à Educação Especial e que tentam estabelecer parcerias entre os professores da Educação Especial e professores da rede regular de ensino; 2) as que se caracterizaram por apoiar professores de Educação Especial (salas especiais e de recursos), bem como professores regulares, trabalhando pela intermediação entre esses professores, alunos, familiares e outros profissionais de Educação, Saúde e Assistência social e 3) as que oferecem apoio apenas a professores regulares, a partir de reuniões, atendimento a solicitações e acompanhamento. Alguns entrevistados apontaram a importância da função da escuta, inerente à profissão de psicólogo e que é demandada por professores que se angustiam quando se deparam com a deficiência, o que Ihes traz uma realidade diferente e exige mudanças de concepção e método.

Também compareceu no discurso dos psicólogos a importância da "Educação para todos", com ênfase na qualidade da Educação como meio para o desenvolvimento e a socialização de todos os alunos, inclusive aqueles com necessidades educacionais especiais. Alguns psicólogos apontaram a necessidade de que a escola esteja comprometida em atender a diversidade, e busque formas de lidar com as diferenças e de trabalhar com os alunos na própria escola, ao invés de se isentar desta responsabilidade ao encaminhar tais alunos a especialistas. Além disso, defendem que a escola não deve receber os alunos com deficiência apenas para cumprimento da lei, mas, partindo do pressuposto de que esses estudantes têm a capacidade de aprender e se desenvolver, deve se adequar às necessidades deles e propiciar condições adequadas em sala de aula para que seu desenvolvimento ocorra de fato, com garantia da qualidade do ensino:

Nós queremos que ele se desenvolva na escola, e não fique apenas lá na escola porque ele tem direito, mas que ele fique e se desenvolva. Eu acho que essa questão do desenvolvimento dele está muito ligada às práticas de sala de aula; a escola tem uma modificação também... a qualidade da escola mesmo... até para poder atender as necessidades desses alunos, que eles são capazes. (Psicólogo 05).

Um dos psicólogos enfatizou que a intervenção no âmbito da Educação Inclusiva deve envolver as relações no interior do contexto escolar, de forma que essas se transformem para possibilitar processos de escolarização de boa qualidade. Parte-se do princípio de que a inclusão de alunos com necessidades educacionais especiais nas escolas regulares deve vir acompanhada de transformações na escola, introduzindo adaptações materiais (acessibilidade física, de mobiliário, recursos pedagógicos etc.) e imateriais (nas relações humanas e nos métodos de ensino). Além disso, certos casos requerem recursos auxiliares, o que indica a necessidade de articulação intersetorial e interprofissional.

Muitas vezes, a escolarização desses alunos é realizada junto a uma série de acompanhamentos dos mais diversos especialistas, como fonoaudiólogos, fisioterapeutas, pediatras, neurologistas, entre outros. O psicólogo também entra nesse rol de profissionais especialistas, e sua solicitação por parte dos educadores por vezes toma a forma de busca por orientação sobre qual seria a melhor forma de ensinar uma criança ou adolescente com necessidades educacionais especiais. É possível identificar nessa procura por atendimento especializado a ideia de que a escolarização desses estudantes necessita do acompanhamento de profissionais da saúde para ocorrer, como se sem essa condição ela não se sustentasse. Cabe cuidar para que esse apoio não ganhe contornos que decidam sobre a educabilidade ou não desses alunos, como solução segura que direcione o fazer dos educadores, considerando haver um contexto de fragilização desses profissionais, que se sentem incapazes e desprovidos de competência para promover a aprendizagem dessas crianças. Ajudar a pensar conjuntamente, somando conhecimentos e mantendo a centralidade do educador nas decisões sobre o seu fazer, permanece como desafio para os profissionais de outras áreas que aspiram sair do lugar do técnico especialista e almejam fortalecer a confiança dos educadores em seus próprios saberes (Angelucci \& Lins, 2007).

Ao analisarmos as práticas que, de acordo com os psicólogos foram consideradas bem-sucedidas, alcançando os objetivos propostos, encontramos: a constituição de um centro de apoio à Educação Inclusiva, a transferência de $90 \%$ de alunos da classe especial para classes regulares de ensino, ações de combate à violência na escola e a inclusão de pessoas com deficiência no mercado de trabalho. Além disso, psicólogos destacaram o fato de terem conquistado, junto à Secretaria de Educação, a mudança de foco do trabalho de um atendimento individual do aluno para uma atuação institucional e centrada na formação. Mas alertam que essa mudança de concepção também precisa ser aceita pelos educadores, bem como pelos colegas de outras Secretarias, que não reconhecem o trabalho institucional como uma atuação legítima de psicólogos. Algumas equipes mencionaram um visível esforço por parte dos profissionais mais antigos e até da própria coordenação para mudar essa visão tradicional de que o psicólogo só faz avaliação psicológica e atendimento clínico.

Com relação a ações que não conseguiram repercutir positivamente na rede de Educação, são citados casos de crianças com deficiências que são considerados cristalizados, demandando formas de atuação mais específicas em que seja possível a articulação com educadores e outros profissionais que se proponham, de fato, a acompanhar tais 
alunos. É mencionada também a realização de curso de formação em alfabetização que não acarretou mudanças em sala de aula.

Destacam-se ainda como desafio a reversão das tendências a encaminhar alunos para salas especiais após avaliação psicológica e a transformar problemas educacionais em questões médicas, a serem indevidamente tratadas com medicamentos - a exemplo do que ocorre com o excesso de alunos diagnosticados com transtornos como o Transtorno de Déficit de Atenção com ou sem Hiperatividade (TDA/ TDAH) e dislexia. O psicólogo ganha destaque como profissional que procura sensibilizar os educadores quanto ao excesso de diagnósticos e estabelecer as relações do contexto social e político com a organização do sistema educacional e a patologização do espaço escolar, buscando devolver a discussão sobre o aprendizado e o desenvolvimento das crianças medicalizadas para o âmbito pedagógico (Collares \& Moysés, 1994).

Alguns psicólogos relataram que determinadas práticas oficiais parecem excluí-los dos processos de decisão, retirando-Ihes a autonomia, a possibilidade de ações coletivas e fazendo-os sentirem-se solitários. Entretanto, os psicólogos consideraram que não há, de forma geral, limitações criadas por diferentes concepções teórico-metodológicas no interior da secretaria de Educação.

A fim de enfrentar dificuldades como essas relatadas, foi apontada a necessidade de formação continuada dos psicólogos e membros da equipe de trabalho, com destaque para o trabalho de supervisão como um instrumento importante de atualização e de compreensão da prática profissional. É sabido que o processo de autocrítica e reconstrução do trabalho deve ser ininterrupto e, para tanto, os psicólogos destacaram como decisiva a realização de assessorias e cursos externos:

A partir do momento que eu consegui me embasar melhor teoricamente, eu pude ir conversar na escola de um jeito diferente. Por que antes eu ia de que jeito? Com um jeito clínico, uma coisa meio congelada, individualizada. Então, assim, agora eu vou com o modelo em contexto, diferente do que eu ia (Psicólogo 06).

Dessa forma, os psicólogos enfatizam a importância da relação teoria-prática para a construção de novas práticas, que expressem o compromisso do psicólogo com as questões da Educação (Tanamachi \& Meira, 2003). Eles demonstram efetivar tais compromissos em seu cotidiano profissional ao buscarem voltar sua atenção para o cotidiano escolar e nele intervir, junto a todos os segmentos que a compõem, para construir relações que favoreçam a escolarização de todos os estudantes.

\section{Conclusão}

Conforme descrito no início deste texto, foram entrevistados nesta pesquisa psicólogos da rede pública de
Educação que haviam evidenciado, em etapa anterior do estudo, indícios de uma atuação coerente com pressupostos teórico-metodológicos de uma perspectiva crítica em Psicologia Escolar e Educacional. Assim, foi possível identificar no discurso desses profissionais sobre suas práticas e concepções os seguintes elementos:

- foco de intervenção no processo de escolarização e nas relações que compõem o contexto escolar, com grande diversidade de estratégias de atuação e público-alvo amplo, em oposição ao atendimento clínico tradicional centrado no aluno e/ou família e na realização de diagnósticos e aplicação de testes psicológicos;

- $\quad$ presença de concepção sobre a atuação do psicólogo escolar como mediador entre os participantes do processo educacional;

- participação na formação dos educadores e promoção de espaços de discussão com professores e gestores;

- crítica à medicalização da Educação e à patologização no contexto escolar.

Os psicólogos também mencionaram uma série de desafios a serem enfrentados na sua atuação profissional, advindos de condições adversas de trabalho. Identificam tais condições como: a baixa remuneração, a burocratização e o excesso de trabalho, a ausência de plano de carreira, o desvio de função, a descontinuidade frente às mudanças de gestão e a escassez de apoio institucional para a formação continuada. A questão da representação social da profissão centrada no modelo clínico, fortemente presente entre os educadores, também foi citada como um desafio na efetivação de uma prática crítica e alicerçada em dimensões históricas e sociais.

Houve destaque para a atuação do psicólogo no âmbito da Educação Inclusiva e a necessidade de envolver toda a escola (funcionários, professores, pais, comunidade local) nesse processo, atentando-se para os preconceitos em relação à deficiência. Defendeu-se a leitura institucional das queixas escolares, evitando, assim, transferi-las à Saúde ou exclusivamente à Educação Especial.

Por fim, nota-se um movimento de avanço em direção à construção de práticas profissionais pautadas nos conhecimentos teórico-práticos que vêm sendo desenvolvidos no campo acadêmico por autores da perspectiva crítica em Psicologia Escolar, expresso, inclusive, por meio do comprometimento dos psicólogos com a efetivação do direito à educação pública e de qualidade a todos os estudantes.

Considera-se, portanto, a necessidade de realização de novos estudos que aprofundem temas e questões apresentadas neste artigo, bem como se aproximem do grupo de psicólogos que assumem, em suas práticas, concepções distintas daquelas aqui apresentadas e analisadas. 


\section{Referências}

Aguiar, W. M. J. (2002). Professor e Educação: realidades em movimento. Em E. Tanamachi, M. Rocha \& M. Proença (Orgs.), Psicologia e Educação: desafios teórico-práticos. São Paulo: Casa do Psicólogo.

Angelucci, C. B. \& Lins, F. R. S. (2007). Pessoas significativamente diferentes e o direito à educação: uma relação atravessada pela queixa. Em B. P. Souza (Org.), Orientação à queixa escolar. São Paulo: Casa do Psicólogo.

Bock, A. M. B. (2003). Psicologia da Educação: cumplicidade ideológica. Em M. E. M. Meira \& M. A. M. Antunes (Orgs.), Psicologia Escolar: Práticas Críticas. São Paulo: Casa do Psicólogo.

Bogdan, R. C. \& Biklen, S. K. (1994). Investigação Qualitativa em Educação. Porto, Portugal: Porto Editora.

Collares, C. L. \& Moysés, M. A. A. (1994). A transformação do espaço pedagógico em espaço clínico (A Patologização da Educação). Série Ideias (23), São Paulo, FDE, 25-31.

Conselho Regional de Psicologia de São Paulo \& Grupo Interinstitucional Queixa Escolar (Orgs.) (2010). Medicalização de crianças e adolescentes: conflitos silenciados pela redução de questões sociais a doenças de indivíduos. São Paulo: Casa do Psicólogo.

Ezpeleta, J. \& Rockwell, J. (1986). Pesquisa Participante. São Paulo: Cortez.

Freller, C. C. (2001). Histórias de indisciplina escolar: o trabalho de um psicólogo numa perspectiva winnicottiana. São Paulo, Casa do Psicólogo.

Galdini, V. R. \& Aguiar, W. M. J. (2003). Intervenção junto a professores da rede pública: potencializando a produção de novos sentidos. Em M. E. M. Meira \& M. A. M. Antunes (Orgs), Psicologia Escolar: Teorias Críticas. São Paulo: Casa do Psicólogo.

Kupfer, M. C. M. (2010). O que toca à/a Psicologia Escolar. Em A. M. Machado \& M. P. R. Souza (Orgs.), Psicologia Escolar: em busca de novos rumos (5a. ed.). São Paulo: Casa do Psicólogo.

Leal, Z. F. R. G, Facci, M. G. D., \& Souza, M. P. R. (Orgs) (2014). Adolescência em foco: contribuições para a Psicologia e para a Educação. Maringá: Eduem.

Lüdke, M. \& André, M. E. D. A. (1986). Pesquisa em Educação: abordagens qualitativas. São Paulo: EPU.

Machado, A. M. \& Proença, M. (Orgs.). (2004). Psicologia Escolar: em busca de novos rumos. São Paulo: Casa do Psicólogo.
Meira, M. E. M. (2002). Psicologia Escolar: pensamento crítico e práticas profissionais. Em E. R. Tanamachi, M. Proença \& M. Rocha (Orgs.), Psicologia e Educação: desafios teórico-práticos. São Paulo: Casa do Psicólogo.

Meira, M. E. M. \& Antunes, M. A. M. (Orgs). (2003a). Psicologia Escolar: Práticas Críticas. São Paulo: Casa do Psicólogo.

Meira, M. E. M. \& Antunes, M. A. M. (Orgs). (2003b). Psicologia Escolar: Teorias Críticas. São Paulo: Casa do Psicólogo.

Ministério da Educação (2001). Diretrizes Nacionais para a Educação Especial na Educação Básica. Brasil: MEC.SEESP. Recuperado: 18 set. 2013. Disponível: http://portal.mec.gov.br/seesp/arquivos/ pdf/diretrizes.pdf.

Ministério da Educação (2008). Política Nacional de Educação Especial na Perspectiva da Educação Inclusiva. Brasília: MEC/ SEESP, 2008. Recuperado: 18 set. 2013. Disponível: http://portal. mec.gov.br/arquivos/pdf/politicaeducespecial.pdf.

Patto, M. H. S. (2000). Mutações do cativeiro: escritos de Psicologia e Política. São Paulo: Hacker Editores/Edusp.

Patto, M. H. S. (2005). Exercícios de indignação: escritos de Educação e Psicologia. São Paulo: Casa do Psicólogo.

Prilleltensky, I. \& Fox, D. (1997). Critical Psychology: An Introduction. London: Sage Publications.

Rockwell, E. (2009). La experiência etnográfica. Paidós: Argentina.

Sayão, Y. \& Guarido, R. L. (2010). Intervenção psicológica em creche/ pré-escola. Em A. M. Machado \& M. P. R. Souza (Orgs.), Psicologia Escolar: em busca de novos rumos (5a. ed.). São Paulo: Casa do Psicólogo.

Souza, B. P. (Org.) (2010). Orientação à queixa escolar (2a. ed.). São Paulo: Casa do Psicólogo.

Souza, M. P. R. (1996). A queixa escolar e a formação do psicólogo. Tese de Doutorado, Instituto de Psicologia, Universidade de São Paulo, São Paulo, SP.

Souza, M. P. R. (2010). A atuação do psicólogo na rede pública de educação: concepções, práticas e desafios. Tese de Livre Docência, Instituto de Psicologia, Universidade de São Paulo, São Paulo, SP.

Souza, M. P. R. (2011). Retornando à patologia para justificar a não aprendizagem escolar: a medicalização e o diagnóstico de transtornos de aprendizagem em tempos de neoliberalismo. Em Conselho Regional de Psicologia de São Paulo \& Grupo Interinstitucional Queixa Escolar (Orgs.), Medicalização de crianças e adolescentes: conflitos silenciados pela redução de questões sociais a doenças de indivíduos. São Paulo: Casa do Psicólogo. 
Souza, M. P. R. \& Rocha, M. L. (2011). Políticas Educacionais: legislação, formação profissional e participação democrática. Em M. G. D. Facci, M. E. M. Meira, \& S. C. Tuleski (Orgs.), A exclusão dos incluídos: uma crítica da Psicologia da Educação à patologização e medicalização dos processos educativos (1a ed.). Maringá: UEM, v. 1, p. 345-370.

Souza, M. P. R., Silva, S. M. C., \& Yamamoto, K. (Orgs) (2014). Atuação do psicólogo na Educação Básica: concepções, práticas e desafios. Uberlândia: EDUFU.

Tanamachi, E. R. (1992). Psicologia Escolar: Tendências e avanços da Psicologia na educação escolar. Dissertação de Mestrado, Universidade Estadual Paulista, Marília, SP.

Tanamachi, E. R. (1997). Visão crítica de Educação e de Psicologia: elementos para a construção de uma visão crítica de Psicologia Escolar. Tese de Doutorado, Universidade Estadual Paulista, Marília, SP.

Tanamachi, E. R. (2002). Mediações teórico-práticas de uma Visão
Crítica em Psicologia Escolar. Em E. R. Tanamachi, M. Proença \& M. Rocha (Orgs.), Psicologia e Educação: desafios teóricopráticos. São Paulo: Casa do Psicólogo.

Tanamachi, E. R. \& Meira, M. E. M. (2003). A atuação do psicólogo como expressão do pensamento crítico em Psicologia e Educação. Em M. E. M. Meira. \& M. A. M. Antunes (Orgs.), Psicologia Escolar: Práticas críticas. São Paulo: Casa do Psicólogo.

Tanamachi, E., Rocha, M., \& Proença, M. (Orgs.). (2000). Psicologia e Educação: desafios teórico-práticos. São Paulo: Casa do Psicólogo.

Viégas, L. \& Angelucci, C. B. (Orgs.) (2006). Políticas Públicas em Educação: uma análise crítica a partir da psicologia escolar. São Paulo, Casa do Psicólogo.

\section{Sobre os autores}

Marilene Proença Rebello de Souza (mprdsouz@usp.br)

Instituto de Psicologia da Universidade de São Paulo - Professora Titular.

Aline Morais Mizutani Gomes (alinemizu@gmail.com)

Instituto de Psicologia da Universidade de São Paulo - Mestre.

Ana Karina Amorim Checchia (anakarina.ak.ac@gmail.com) Instituto de Psicologia da Universidade de São Paulo - Doutora.

Juliana Sano de Almeida Lara (juliana.sano@gmail.com)

Instituto de Psicologia da Universidade de São Paulo - Mestre.

Marcelo Domingues Roman (mdroman@hotmail.com)

Universidade Federal de São Paulo - Campus Baixada Santista. Departamento de Políticas Públicas e Saúde Coletiva - Professor Doutor.

Agências financiadoras: CNPq e FAPESP 